\title{
Effect of Abdominal Massage on Gastrointestinal Complications and Intra-Abdominal Pressure of Critical-Enteral-Feed Patients: A Randomized Control Trial
}

\author{
Amal Ismael Abdelhafez ${ }^{1,2}$ Manal Mohamed Abd Elnaeem ${ }^{1}$ \\ 1.Critical Care and Emergency Nursing, Faculty of Nursing, Assiut University, Egypt \\ 2.College of Applied Medical Science, King Faisal University
}

\begin{abstract}
Background: critically ill patient need a nursing practice that can enhance him to get all benefits of enteral feeding and overlapping the GI complications and maintain the intra-abdominal pressure.Objective: This work aimed to explore the effect of abdominal massage on gastrointestinal complications and intra-abdominal pressure of critical- enteral-feed patients. Methods: A randomized controlled trial was applied on 74 eligibly enteral-fed patients at Trauma and General ICUs. Of these, the trail was completed on sixty patients who distributed randomly to equal intervention and control groups. The manipulation was two times for $15 \mathrm{mins}$ of abdominal massage for five days. The effect was measured on enteral feeding complications (GRV, abdominal circumference and distention, vomiting) and intra-abdominal pressure as compared with control group who didn't receive the massage. Results: the GRV difference between the massage group and control group subjects was statistically significant $(\mathrm{P}<0.001)$ in the $3^{\text {rd }}, 4^{\text {th }}$, and $5^{\text {th }}$ days indicating higher GRV among control group. The abdominal circumference between the five days was not significantly in the two groups. The difference between the two groups in relation to the distension was statistically significant $(p<0.05)$ in day 3,4 and5. None of intervention patients were vomited along the study period (5days) in compared to $5 \%$ of control patients without statistical significant. Conclusions: The abdominal massage was significantly effective in lowering GRV, preventing distension and avoiding vomiting. Besides, the abdominal massage maintained the IAP without any statistical significant support. Therefore, it is recommended that this practice can be applied as a caring procedure in the daily ICU care program.
\end{abstract}

Keywords: abdominal massage, gastrointestinal complications, intra-abdominal pressure, enteral-fed patients DOI: $10.7176 / \mathrm{JHMN} / 64-05$

Publication date:July $31^{\text {st }} 2019$

\section{I- Introduction:}

1.1. Importance of enteral feeding method:

Food is one of the basic human physiological needs which must fulfill to live (McLeod, 2007). Likewise, the critically ill patients must get food support which will help him also to bypass successfully the critical health problems. As all know, the critical patients get food either by enteral tube or parenteral pathway. Enteral method has evidenced top advantages than parenteral feeding (McClave et al., 2016). In the aspect, enteral pathway enhances the normal mechanisms of gastro-intestinal tract and has lesser complications than parenteral feeding especially in term of healing process and hospital stay. The enteral pathway helps to maintain peristalsis, improves blood supply, strengthens the immune system and decrease the catabolic state associated with injury (Ros, McNeill, \& Bennett, 2009). It is recommended to start the enteral feeding of stable critical patients within first 24 : 48 hr. of admission (Bourgault, Ipe, Weaver, Swartz, \& O'Dea, 2007). From the other side of coins, the enteral- feeding-pathway can develop complications which worsen the patient's state. For example, infection, aspiration and pneumonia for ventilated patient (Vazquez-Sandoval, Ghamande, Surani, \& therapeutics, 2017).

\subsection{Gastrointestinal complication of ICU' patients:}

Patient in critical illness stage has many barriers and challenges which keep him away to get all benefits of enteral-feeding and affect his nutritional status, recovery process and hospital days (Dobson \& Scott, 2007). Most of these barriers are gastrointestinal (GI) complications such as vomiting (by 12.2\%), diarrhea, abdominal distention, constipation, and high gastric residual volume (by 32-39\%) which can be prohibited by early identifying signs and symptoms of feeding intolerance (Morton \& Fontaine, 2013; Taylor, 2016). It is known that these complications whether are causal or effect can lead to an inability to achieve nutritional target in severely illness patients. Up to $50 \%$ of enteral fed patients can develop GI intolerance which usually manage in clinical practice areas by interrupting or ceases the feeding schedule (Warren, 2016). In a study done by (Kuslapuu, Jõgela, Starkopf, Blaser, \& Nursing, 2015) found that the enteral nutrition was interrupted in $76 \%$ and stopped in $30 \%$ of their patients due to excess GRV. Moreover, many studies reported that almost two thirty of patients who developed enteral nutrition complications didn't get their required calories (Elpern, Stutz, Peterson, Gurka, \& Skipper, 2004; Mentec et al., 2001; Moreira \& McQuiggan, 2009) 


\subsection{Intra-abdominal pressure (IAP) of enteral-fed patients}

The pressure arising from abdominal organs, viscera and abdominal wall is accepted to be less than $5 \mathrm{mmHg}$ in adult. Increasing the IAP level is expected among the intensive care patients according to many factors especially that affect the stability of abdominal cavity either by the pathology of the disease itself or the treatment modalities. However, the abdominal compliance is limited and is considered intra-abdominal hypertension (IAH) as 12: $20 \mathrm{mmHg}$ and abdominal compartment syndrome (ACS) as more than $21 \mathrm{mmHg}$ (Christensen, Craft, \& Nursing, 2018). In literature, IAP disturbs the organ tissue perfusion, possibly leading to severe ischemic or circulatory changes. It was found also correlation between the increased IAP and organ dysfunction which leading to worsening the patient's status and used now as predictors of morbidity and mortality of critically ill patients (Dehghan, Mehdipoor, \& Ahmadinejad, 2018; Malbrain \& De Waele, 2013).

\subsection{Role of critical care nurses (CCN)}

Critical care nurses are usually occupied with improving the patient' status and trying to decrease his suffering or complications derived from ICU management. Critical care nurses are in charge for the assessment of enteral-fed patients. Most of enteral feeding complications that progress as a result of feeding intolerance can be prevented by nursing care. According to nurse scholars, nutrition is a part of nursing care as well as medical treatment (Persenius, Larsson, Hall-Lord, \& Nursing, 2006) (Marshall, West, \& Nursing, 2006). Nurses perform a significant role starting from the assessment phase of a patient's requirement of feeding, until planning and applying the feeding safely and efficiently. Most of the success in enteral tube feeding depends on the role of $\mathrm{CCN}$ in giving the nutrition, continuous monitoring and evaluation the patient (N. Uysal, Eser, \& Akpinar, 2012). The accountability of IAP monitoring usually is under $\mathrm{CCN}$ role through continuous observation and identifying of subtle and dynamic changes in the status of critically ill patients (Newcombe, Mathur, \& Ejike, 2012). Previously, (Cole \& Shanley, 1998) stated that massage is a therapeutic, complementary method in terms of nurses' enhancing professional roles. Recently, (Dehghan, Mokhtarabadi, Heidari, \& Medicine, 2018; Ghaedi, Dehghan, Salari, Sheikhrabori, \& medicine, 2017) stated that the massage therapy as a type of complementary therapy can be used in palliative management.

\subsection{Abdominal massage:}

Abdominal massage is one of complementary therapy that can be applied to enhance the digestive system functions, improve the intestinal movements and decrease intra-abdominal pressure (Preece \& Midwifery, 2002; Pyszora \& Krajnik, 2010; Sinclair \& therapies, 2011). Some researchers studied the effect of abdominal massage on the prevention or treatment the enteral feeding complications. For example, (Kahraman \& Ozdemir, 2015), and (N. Uysal et al., 2012) found that abdominal massage decreased the residual volume and distention in patients fed by a gastric tube among the mechanically ventilated and neurosurgical/medical patients respectively. Other studies publicized that abdominal massage reduced constipation among patients with multiple sclerosis with no adverse effects (McClurg, Hagen, Hawkins, \& Lowe-Strong, 2011), chronic constipation(Lämås, Lindholm, Stenlund, Engström, \& Jacobsson, 2009), and cancer (Lai et al., 2011).

Abdominal massage can stimulate parasympathetic activity that enhancing the gastrointestinal function. Abdominal massage accelerates peristalsis by changing intra-abdominal pressure and producing a mechanical and reflexive effect on the intestines, decreasing abdominal distension and increasing intestinal movements (Harrington \& Haskvitz, 2006) (Liu et al., 2005). Avery few studies applied the abdominal massage to examine its effect on GI intolerance and intra-abdominal pressure in randomized trials. The researchers recommended further research on this topic with different patients, diagnosis and areas to generalize and compare the results (Lämås, Graneheim, \& Jacobsson, 2012; McClurg et al., 2011). Therefore, the present study aims to explore the effect of abdominal massage practice on enteral feeding complications and intra-abdominal pressure of enteralfed patients

\subsection{Nursing implication of this study:}

Gastrointestinal complications still the major problem that facing the critically ill patients' especially enteral-fed one and can increase the suffering (Mohamed et al., 2013). In the meantime, several studies have focused on the roles of ICU' nurses to perform such intervention (Jamaati et al., 2015). The main focus problem that studied the effectiveness of abdominal massage on patients was constipation. Therefore, this research was carried out trying to help the nurses to find out the solution for all GI complications (GRV, abdominal circumference, Distention and vomiting) by applying the costless, safe and simple strategy which is abdominal massage. Moreover, this study aimed to explore the effect of abdominal massage on IAP reading for first time. Previously, the authors assumed the effectiveness of massage on IAP without actually randomized studies. 


\section{Methods}

2.1. Design: A randomized controlled trial was applied in this study to explore the effect of abdominal massage (independent variable) on enteral feeding complications and intra-abdominal pressure (dependent variables) of enteral-fed patients.

\subsection{Settings and patients:}

The study was conducted at 2018 (March to September) in the Trauma and General ICUs at Assiut University Hospitals. Patients' families gave informed consent prior to the study. According to Power Analysis and Sample Size (PASS) program with 0.80 powers and 0.05 margin errors, the total showed 60 patients.

Inclusion criteria were intermittent enteral-fed, adult age, physiological parameter stability, free GI assessment and using only $\mathrm{H} 2$ receptor antagonists as gastric prophylaxis. The exclusion conditions were under sedation, GI surgery, trauma, pain and ileus, and using pro-kinetic agents. To control variables and prevent contamination of data, the patient who developed diarrhea or constipation within study period were excluded because of diarrhea can be related to infection and the constipation related to immobility.

\subsection{Randomization:}

The patients were randomly assigned to equal control and intervention patients. The researcher made 30 cards with symbol A (control patient) and 30 card with symbol B (intervention patient) and put it in a box. Then, the researcher picked randomly each card to assign patient per group until emptying the box. The patients who discharged, died or cease EN were not included in the study (see the flow chart).

2.4. Tool: the researcher developed two-part tool to collect the data, one including the patient' medical characteristics (age, sex, diagnosis) and the second part for following the GI information (abdominal girth, distension, vomiting, GRV, and intra-abdominal pressure).

2.5. The tool was verified for content validity. First, the researcher designed the tool based on valuable scientific publications and books (Emly, 2008). Second, the tool distributed to five nursing and anesthesiologist staff at Assiut University. Then, their opinions were followed as mark the patient' status as stable or unstable instead of MV setting' data and vital signs. Finally, the study was piloted on three patients to test the feasibility and applicability of the tool then their results were excluded from the actual study.

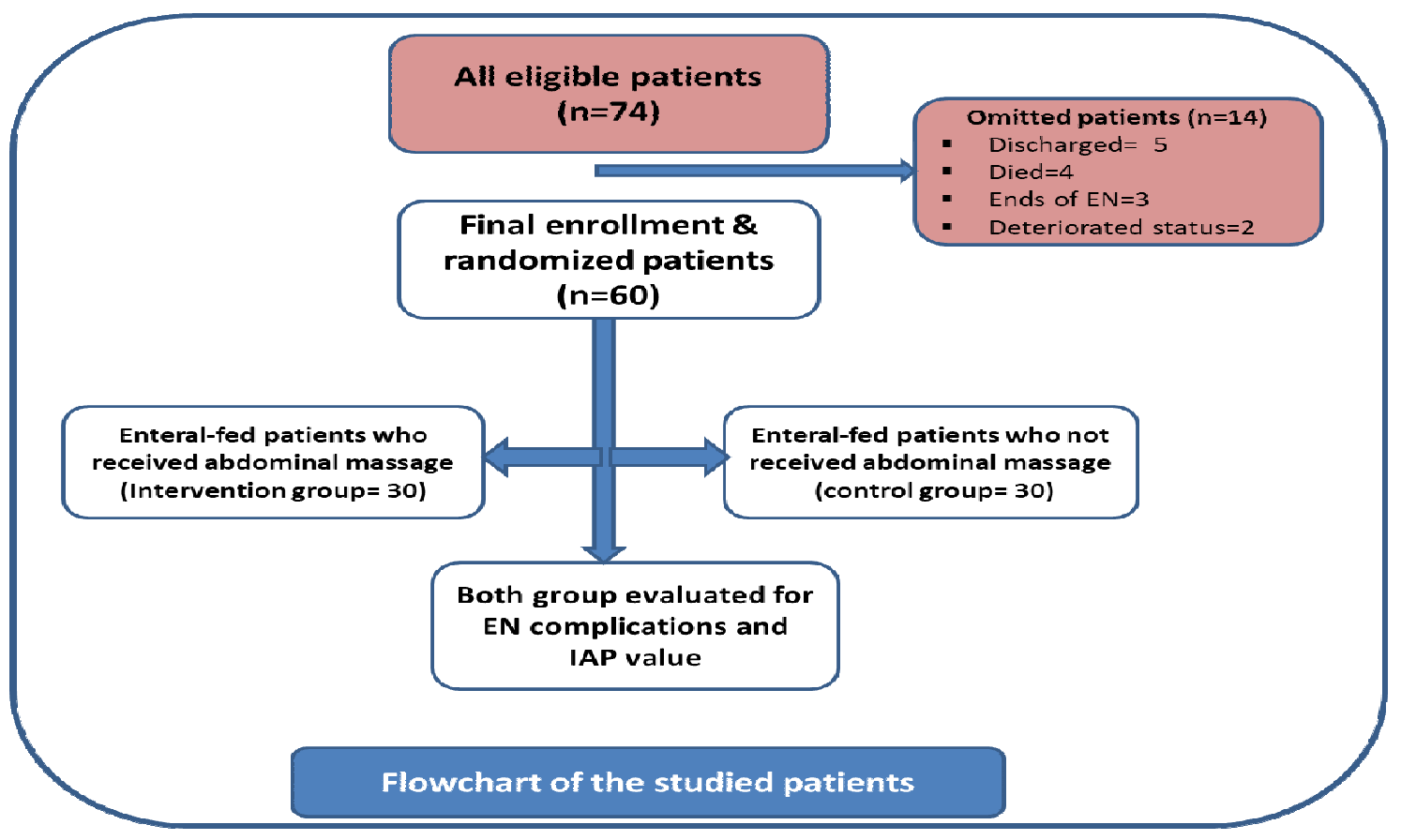

\subsection{Intervention:}

- Both group were received the routine ICU protocol of the intermittent enteral feeding as the type, frequency and amount and flow rate of formula per day. 
- The control patients get their usual ICU care without applying the abdominal massage. The patients assessed to fill the study tool to compare its results with intervention group.

- The researcher was referred to one of the physiotherapy professors at Assuit University Hospital and got abdominal massage training.

- The intervention patients received the abdominal massage two times per day at 10.30 and 20.30 hours for 15 minutes before feeding time to avoid aspiration for five consecutive days.

- Abdominal massage practice: Put the patient in supine position, straight the legs and stand on right side. The massage technique consists of eight steps see Fig (1). It started in a left to right direction over the intestines on the abdominal wall. The main steps of massage are superficial effleurage, deep circular stroking, petrissage, and vibration (N. J. E. J. o. I. M. Uysal, 2017).

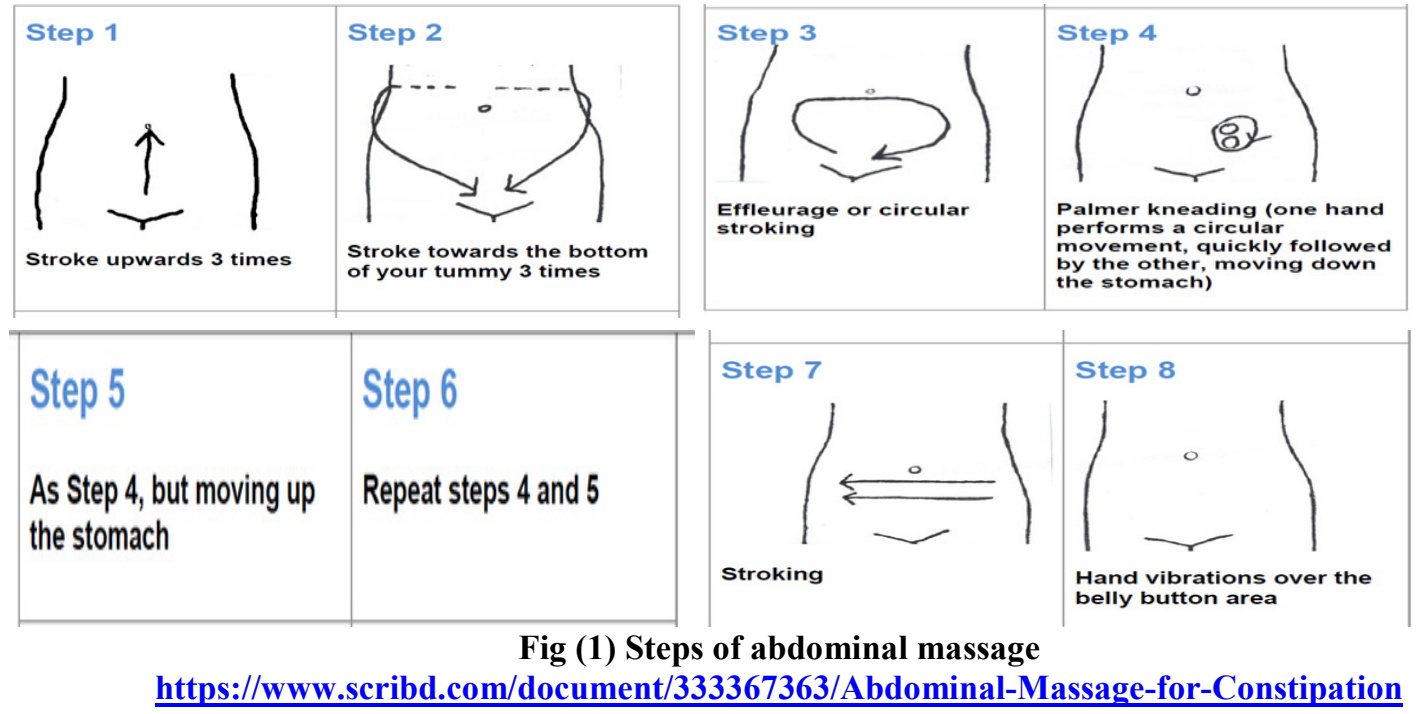

\section{- Gastric residual volume:}

Both groups were assessed for GRV before each feeding. First, the feeding tube position was confirmed by listening to $20 \mathrm{ml}$ of injecting air with a stethoscope at the epigastric area. Then, aspirate the stomach content slowly until no further content. The aspirated content measured by measuring container and discarded according to the ICU guidelines (Warren, 2016).

\section{- Abdominal distension:}

Both groups were assessed for distension by palpation and percussion. No distension means that the abdomen is soft, moving and not tense. Distended abdomen means hard, tender, bloating and increase in abdominal diameter. The circumference was measured before the massage (Forbes \& Watt, 2015; N. Uysal et al., 2012)

\section{- Vomiting:}

All patients were assessed for developing vomiting. According to the ICU guidelines, the feeding was interrupted and the tube feeding was opened. The patient was re-fed after showed a positive feeding test.

\section{- Intra-abdominal pressure (IAP):}

It was measured by urinary catheter; put the patient in supine position, employs a Y-set, the zero reference was superior iliac crest at the mid-axillary line. Each IAP value was obtained by manometer $(\mathrm{cmH} 2 \mathrm{O})$ and recalculated in millimeter mercury using the conversion factor $(1 \mathrm{cmH} 2 \mathrm{O}=0.74 \mathrm{mmHg})$. The measuring system is closed and the urinary drainage bag clamp released at the end of the procedure (Kuteesa et al., 2015).

\section{Ethical considerations}

The protocol has been approved of by ethical committee of Faculty of Nursing and head of ICUs at Assuit University. Confidentiality, anonymity and privacy of patients were maintained. The study followed common ethical principles in clinical research. A written consent was filled from patients or family' member after explaining the purpose and process of the study.

\section{Statistical analysis:}

The study' data were analyzed using SPSS 11.0 (SPSS Inc. Chicago, IL). The comparisons of the basic variables, including age, sex, and diagnosis items were investigated between the two groups using frequency (percent) and mean (standard deviation), independent t-test and chi-squared test. The one-way analysis of variance (ANOVA) 
is an omnibus test statistic and was used to determine whether there are any statistically significant differences between the means of IAP and circumference at the five days. The independent t-test is an inferential statistical test that determines whether there is a statistically significant difference regarding mean of GRV between the two groups. $\mathrm{P}$ values minus 0.05 were considered as significant.

\section{Results}

The basic characteristics (Table 1) reveals no significant between the intervention and the control group. The mean age of intervention group was $48.43+11.49$ and was $44.03+12.84$ among the control group. Sixty percent of intervention and $76.67 \%$ of control patients were male. Head Injury was the first reason for admission into ICUs by $66.67 \%$ of intervention and $60.00 \%$ of control patients.

Table 2 shows that the GRV difference between the intervention group and control group subjects was statistically significant $(\mathrm{P}<0.001)$ in the $3^{\text {rd }}, 4^{\text {th }}$, and $5^{\text {th }}$ days indicating higher GRV among control group. In addition, GRV of intervention group was slightly increased but still within acceptable level (less than 50ml out of $200 \mathrm{ml}$ feeding) through the 5 days. However, GRV of control group was dramatically increased (near to half of $200 \mathrm{ml}$ feeding $)$ significantly $((\mathrm{P}<0.001)$. Table 2 also presents that the abdominal circumference between the five days were not significantly in the two group $(\mathrm{p}=1.000, \mathrm{p}=0.878)$ respectively. However, the difference between the two groups in relation to the distension was statistically significant $(\mathrm{p}<0.05)$ in day 3,4 and5. Regarding vomiting, none of intervention patients were vomited along the study period (5days) in compared to $5 \%$ of control patients without statistical significant.

One-way ANOVA of IAP (Table 3) illustrates that mean of IAP of intervention group in the five days was the same $(8.17 \pm 1.37)$. In the control group the mean of IAP was slightly increased in day 5 than first day (7.87 \pm 2.47$)$ without intra-group statistical significant.

A significant positive correlation between GRV and IAP (figure 2) in the control group ( $\mathrm{r}=0.788)$ and the intervention group $(\mathrm{r}=0.817))$ respectively.

Table (1):- Basic data of the study patients

\begin{tabular}{|c|c|c|c|c|c|}
\hline & \multicolumn{2}{|c|}{ Intervention $(\mathrm{n}=\mathbf{3 0})$} & \multicolumn{2}{|c|}{$\operatorname{control}(n=30)$} & \multirow{2}{*}{ P. value } \\
\hline & n. & $\%$ & n. & $\%$ & \\
\hline \multicolumn{6}{|l|}{ Age group (years) } \\
\hline $20-29$ & 4 & 13.33 & 7 & 23.33 & \multirow{4}{*}{0.611} \\
\hline $30-39$ & 2 & 6.67 & 3 & 10.00 & \\
\hline $40-49$ & 12 & 40.00 & 8 & 26.67 & \\
\hline 50 and more & 12 & 40.00 & 12 & 40.00 & \\
\hline Mean \pm SD & \multicolumn{2}{|c|}{$48.43 \pm 11.49$} & \multicolumn{2}{|c|}{$44.03 \pm 12.84$} & $\bullet 0.167$ \\
\hline \multicolumn{6}{|l|}{ Sex } \\
\hline Male & 18 & 60.00 & 23 & 76.67 & \multirow{2}{*}{0.133} \\
\hline Female & 12 & 40.00 & 7 & 23.33 & \\
\hline \multicolumn{6}{|l|}{ Diagnosis } \\
\hline head injury & 20 & 66.67 & 18 & 60.00 & \multirow{5}{*}{0.222} \\
\hline Pneumonia & 6 & 20.00 & 3 & 10.00 & \\
\hline post arrest & 0 & 0.00 & 2 & 6.67 & \\
\hline pulmonary embolism & 1 & 3.33 & 0 & 0.00 & \\
\hline chest trauma & 3 & 10.00 & 7 & 23.33 & \\
\hline
\end{tabular}

\section{Chi- square test}

$\cdot \mathbf{P}=$ Independent $\mathrm{T}$ - test 
Table (2):- Gastrointestinal complications among intervention and control group.

\begin{tabular}{|c|c|c|c|}
\hline Gastrointestinal complications & Intervention( $\mathbf{n}=\mathbf{3 0})$ & Control $(n=30)$ & $\cdot P$. value \\
\hline GRV out of $200 \mathrm{ml}$ feeding & $($ mean+ SD) & (mean+ SD) & \\
\hline $1^{\text {st }}$ day & $0 \pm 0$ & $0 \pm 0$ & \\
\hline $2^{\text {nd }}$ day & $0 \pm 0$ & $4.77 \pm 14.6$ & 0.079 \\
\hline $3^{\text {rd }}$ day & $16.37 \pm 5.05$ & $51.43 \pm 8.42$ & $<0.001 * *$ \\
\hline $4^{\text {th }}$ day & $20.2 \pm 5.89$ & $64.07 \pm 14.08$ & $<0.001 * *$ \\
\hline $5^{\text {th }}$ day & $24.1 \pm 6.22$ & $76.97 \pm 22.45$ & $<0.001 * *$ \\
\hline$\bullet P$. value & $<0.001$ & $<0.001$ & \\
\hline Abdominal Circumference (cm) & (mean+ SD) & (mean+ SD) & \\
\hline $1^{\text {st }}$ day & $83.17 \pm 7.87$ & $83.43 \pm 7.8$ & - \\
\hline $2^{\text {nd }}$ day & $83.22 \pm 7.79$ & $83.5 \pm 7.73$ & - \\
\hline $3^{\text {rd }}$ day & $83.25 \pm 7.83$ & $83.98 \pm 7.58$ & - \\
\hline $4^{\text {th }}$ day & $83.3 \pm 7.76$ & $84.62 \pm 7.65$ & - \\
\hline $5^{\text {th }}$ day & $83.23 \pm 7.85$ & $85.23 \pm 7.6$ & - \\
\hline$\bullet \cdot P$. value & 1.000 & 0.878 & \\
\hline Abdominal distention (palpitation) & n (\%) & n (\%) & $\cdots P$. value \\
\hline $\mathbf{1}^{\text {st }}$ day (distended) & $0(0.0)$ & $0(0.0)$ & - \\
\hline $2^{\text {nd }}$ day (distended) & $0(0.0)$ & $2(6.67)$ & 0.150 \\
\hline $3^{\text {rd }}$ day (distended) & $2(6.67)$ & $11(36.67)$ & 0.012 \\
\hline $4^{\text {th }}$ day (distended) & $2(6.67)$ & $16(53.33)$ & 0.0002 \\
\hline $5^{\text {th }}$ day (distended) & $2(6.67)$ & $18(60)$ & $<0.001$ \\
\hline Vomiting & n (\%) & $\mathbf{N}(\%)$ & $\bullet \bullet$ P. value \\
\hline $\mathbf{1}^{\text {st }}$ day & $0(0.0)$ & $0(0.0)$ & - \\
\hline $2^{\text {nd }}$ day & $0(0.0)$ & $0(0.0)$ & - \\
\hline $3^{\text {rd }}$ day & $0(0.0)$ & $0(0.0)$ & - \\
\hline $4^{\text {th }}$ day & $0(0.0)$ & $3(10)$ & 0.076 \\
\hline $5^{\text {th }}$ day & $0(0.0)$ & $2(7)$ & 0.150 \\
\hline
\end{tabular}

$\cdot \mathrm{P}=$ Independent samples $\mathrm{t}-$ test

$\bullet \mathbf{P}=$ One-way ANOVA

$\cdots \mathbf{P}=$ Chi- square test

GRV= gastric residual volume

Table (3):- intra-group comparison regarding Intra-abdominal pressure

\begin{tabular}{|l|c|c|}
\hline $\begin{array}{l}\text { Intra-abdominal pressure } \\
(\mathrm{mmHg})\end{array}$ & $\begin{array}{c}\text { Intervention } \\
(\text { mean+ SD) }\end{array}$ & $\begin{array}{c}\text { Control } \\
\text { (mean+ SD) }\end{array}$ \\
\hline $1^{\text {st }}$ day & $8.17 \pm 1.37$ & $7.27 \pm 1.39$ \\
\hline $2^{\text {nd }}$ day & $8.17 \pm 1.37$ & $7.27 \pm 1.39$ \\
\hline $3^{\text {rd }}$ day & $8.17 \pm 1.37$ & $7.4 \pm 1.45$ \\
\hline $4^{\text {th }}$ day & $8.17 \pm 1.37$ & $7.63 \pm 2.3$ \\
\hline $5^{\text {th }}$ day & $8.17 \pm 1.37$ & $7.87 \pm 2.47$ \\
\hline$\bullet P$ Palue & 1.000 & 1.000 \\
\hline
\end{tabular}

$\bullet P=$ One Way ANOVA 


\section{Figure (2): Correlation between GRV and IAP in the control and intervention groups.}
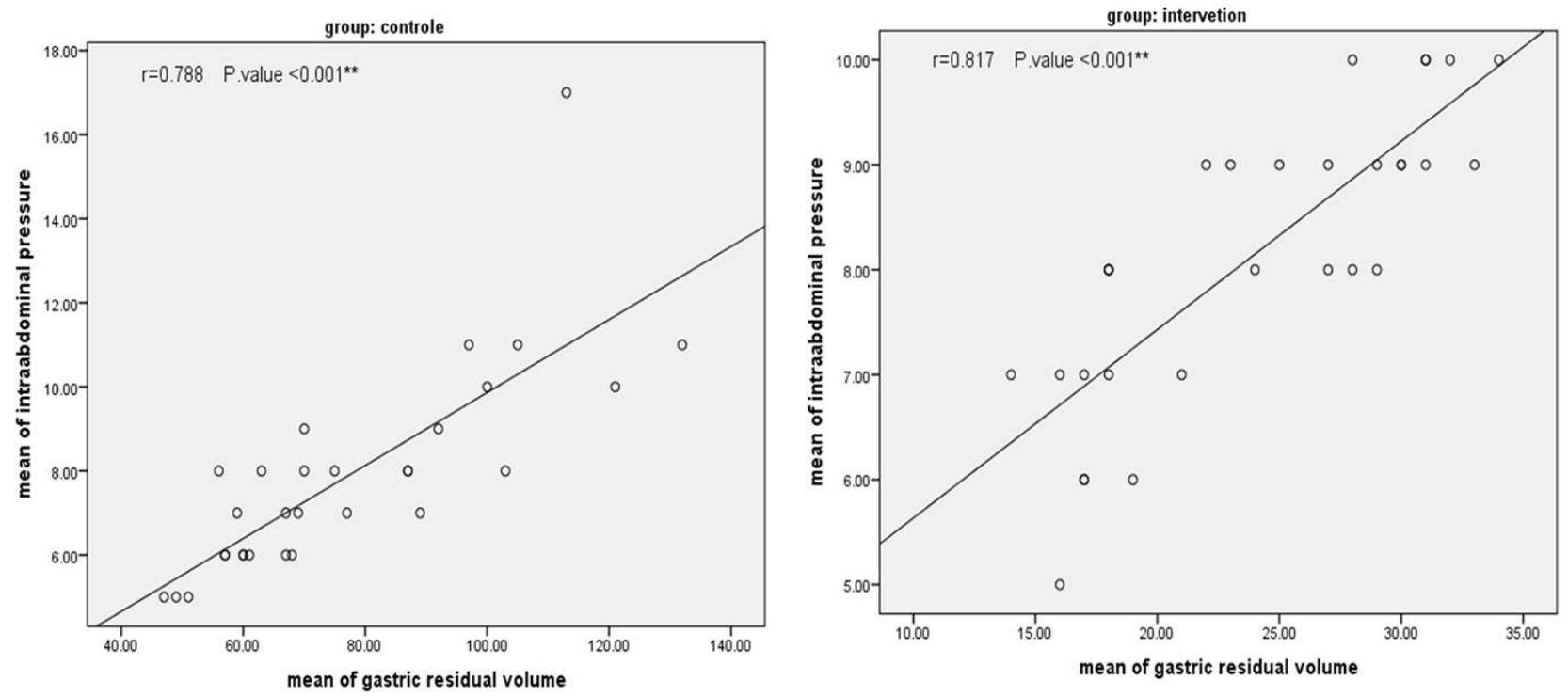

\section{Discussion}

Many CCN stated that the GI complications associated enteral feeding still occurred and need to alleviated. In previous research in the same Trauma ICU setting Abdelhafez A, etal, 2013 found that $57.5 \%$ (40 patients) of control patients developed GI complications; of these $20 \%$ and $12.5 \%$ had vomiting and abdominal distention respectively.

In the current study the GRV among the intervention patients were sloped significantly along the five days of abdominal massage and usually less than control patients. On the contrary, The GRV of the control group is increased significantly along the five days. This may be attributed to the exposure to $15 \mathrm{~min}$ twice per day and for five days can improve the stomach function and increase the speed of gastric empty. This finding is supported by (Bastin, Kulikowski, Piagnerelli, Thirry, \& Vincent, 2004) who found that the amount of GRV was decreased among the abdominal massage group. In 2017, (N. J. E. J. o. I. M. Uysal, 2017) published that $8.0 \%$ of abdominal massage group developed excess GRV as compared with $34.0 \%$ of the control group. In this respect, (Dehghan, Mehdipoor, et al., 2018) reported that GRV was increased significantly in the control group and decreased significantly in the intervention group; however, there was no significant difference between two groups $(\mathrm{P}=0.15)$. in another study (Momenfar, Abdi, Salari, Soroush, \& Hemmatpour, 2018) the abdominal massage lowered the GRV on the second and third day of massage than before the massage ( $p$ value $<0.05$ ).

The study represented that the abdominal massage was not effective on abdominal circumference over the five days. However, the massage was effective on abdominal distension. This is not supported with results of researchers (Dehghan, Mehdipoor, et al., 2018) who applied 15-minute abdominal massage twice a day for three days found a significant difference in the abdominal circumference between the intervention and control groups. Research in 2015 (Wang et al., 2015) who examined the effects of 15-min gentle abdominal massage was administered bi-daily for 3 days showed improvements abdominal bloating significantly.

The current results also revealed that the massage was effective on preventing occurrence of vomiting along the study period (5days). This is may be refer to the massage timing before feeding which enhance gastric empty. Vomiting associated enteral feeding is common and approximately $20 \%$ of critically ill patients suffering from it. Other literatures, reported that the incidence of vomiting ranged from $12 \%$ to $50 \%$ (Momenfar et al., 2018). Nurses should be routinely monitor GRV to ensure gastric empty (Mohamed et al., 2013)

Critically ill patient recognized to have IAP up to $7 \mathrm{mmHg}$, developed IAH at $12 \mathrm{mmHg}$ and considered ACS at $20 \mathrm{mmHg}$ with organ dysfunction (Milanesi \& Caregnato, 2016). In the present trail, the IAP readings of both groups are within accepted level and not exceed to be IAH. This is attributed to the capability of abdominal massage on peristaltic movement, digestion and GI circulation. other researchers (Pyszora \& Krajnik, 2010; Sinclair \& therapies, 2011) stated that the IAP is lowered among the abdominal massage group. The other reason is the inclusion criteria which all patients had stability in the heamodynamic status and no GI problems.

\section{Conclusion:}

According to the findings, increasing evidence supports the effect of abdominal massage on lowering GRV, 
preventing distension and avoiding vomiting. In this study the abdominal massage maintained the IAP without any statistical significant support. However, more research is recommended on this effect. Therefore, it is recommended that this practice can be applied as a caring procedure in the daily ICU care program.

Financial support: none

Acknowledgement

We would like to thank all participated patients and the health care staff at Trauma and General ICUs, Assiut University Hospital for their valuable participation.

\section{Conflict of interest}

We declare that we have no conflict of interest

\section{Author contributions}

Amal Ismael Abdelhafez was responsible for interpretation of data, design, drafting and writing the manuscript.

Manal Mohammed was responsible for database, design, analysis and evaluation of the literature

Both authors have made critical revision of the manuscript, read and approved the final manuscript.

\section{References}

Abdelhafez A. I, abdel Mageed, E., Mehany, M. M., Mohammed, M. A.. (2013). Effect of intermittent enteral feeding schadule on gastrointestinal complications. Assiut Scientific Nursing Journal; 1(1),1-16.

Bastin, R., Kulikowski, B., Piagnerelli, M., Thirry, P., \& Vincent, J. J. I. C. M. (2004). Effect of abdominal massage on gastric emptying in critically ill patients. 30, S83.

Bourgault, A. M., Ipe, L., Weaver, J., Swartz, S., \& O’Dea, P. J. J. C. C. N. (2007). Development of evidencebased guidelines and critical care nurses' knowledge of enteral feeding. 27(4), 17-29.

Christensen, M., Craft, J. J. I., \& Nursing, C. C. (2018). The cardio-respiratory effects of intra-abdominal hypertension: Considerations for critical care nursing practice. 44, 53-58.

Cole, A., \& Shanley, E. J. J. o. a. n. (1998). Complementary therapies as a means of developing the scope of professional nursing practice. 27(6), 1171-1176.

Dehghan, M., Mehdipoor, R., \& Ahmadinejad, M. J. C. t. i. c. p. (2018). Does abdominal massage improve gastrointestinal functions of intensive care patients with an endotracheal tube?: a randomized clinical trial. 30, 122-128.

Dehghan, M., Mokhtarabadi, S., Heidari, F. G. J. J. o. C., \& Medicine, I. (2018). Complementary and alternative medicine usage and its determinant factors among Iranian infertile couples. 15(2).

Dobson, K., \& Scott, A. J. N. i. c. c. (2007). Review of ICU nutrition support practices: implementing the nurse-led enteral feeding algorithm. 12(3), 114-123.

Elpern, E. H., Stutz, L., Peterson, S., Gurka, D. P., \& Skipper, A. J. A. J. o. C. C. (2004). Outcomes associated with enteral tube feedings in a medical intensive care unit. 13(3), 221-227.

Emly, M. (2008). Abdominal massage for constipation. In Therapeutic management of incontinence and pelvic pain (pp. 223-225): Springer.

Forbes, H., \& Watt, E. (2015). Jarvis's physical examination and health assessment: Elsevier Health Sciences.

Ghaedi, F., Dehghan, M., Salari, M., Sheikhrabori, A. J. J. o. e.-b. c., \& medicine, a. (2017). Complementary and alternative medicines: usage and its determinant factors among outpatients in Southeast of Iran. 22(2), 210215.

Harrington, K. L., \& Haskvitz, E. M. J. P. t. (2006). Managing a patient's constipation with physical therapy. 86(11), 1511-1519.

Jamaati, H., Vahedian-Azimi, A., Ebadi, A., Ahmadi, F., Saadat, S., Kashafi, M. B., . . Hashemian, S. M. J. A. o. C. C. M. (2015). Therapeutic Effect of Massage on the Patients in Intensive Care Unit. 1(1).

Kahraman, B. B., \& Ozdemir, L. J. I. j. o. n. s. (2015). The impact of abdominal massage administered to intubated and enterally fed patients on the development of ventilator-associated pneumonia: a randomized controlled study. 52(2), 519-524.

Kuslapuu, M., Jõgela, K., Starkopf, J., Blaser, A. R. J. I., \& Nursing, C. C. (2015). The reasons for insufficient enteral feeding in an intensive care unit: A prospective observational study. 31(5), 309-314.

Kuteesa, J., Kituuka, O., Namuguzi, D., Ndikuno, C., Kirunda, S., Mukunya, D., \& Galukande, M. J. W. J. o. E. S. (2015). Intra-abdominal hypertension; prevalence, incidence and outcomes in a low resource setting; a prospective observational study. 10(1), 57.

Lai, T., Cheung, M., Lo, C., Ng, K., Fung, Y., Tong, M., \& Yau, C. J. C. T. i. C. P. (2011). Effectiveness of aroma massage on advanced cancer patients with constipation: a pilot study. 17(1), 37-43.

Lämås, K., Graneheim, U. H., \& Jacobsson, C. J. J. o. C. N. (2012). Experiences of abdominal massage for constipation. 21(5-6), 757-765. 
Lämås, K., Lindholm, L., Stenlund, H., Engström, B., \& Jacobsson, C. J. I. j. o. n. s. (2009). Effects of abdominal massage in management of constipation - a randomized controlled trial. 46(6), 759-767.

Liu, Z., Sakakibara, R., Odaka, T., Uchiyama, T., Yamamoto, T., Ito, T., \& Hattori, T. J. J. o. N. (2005). Mechanism of abdominal massage for difficult defecation in a patient with myelopathy (HAM/TSP). 252(10), 1280-1282.

Malbrain, M., \& De Waele, J. (2013). Intra-abdominal Hypertension: Cambridge university press.

Marshall, A. P., West, S. H. J. I., \& Nursing, C. C. (2006). Enteral feeding in the critically ill: are nursing practices contributing to hypocaloric feeding? , 22(2), 95-105.

McClave, S. A., Taylor, B. E., Martindale, R. G., Warren, M. M., Johnson, D. R., Braunschweig, C., . . . Nutrition, E. (2016). Guidelines for the provision and assessment of nutrition support therapy in the adult critically ill patient: Society of Critical Care Medicine (SCCM) and American Society for Parenteral and Enteral Nutrition (ASPEN). 40(2), 159-211.

McClurg, D., Hagen, S., Hawkins, S., \& Lowe-Strong, A. J. M. S. J. (2011). Abdominal massage for the alleviation of constipation symptoms in people with multiple sclerosis: a randomized controlled feasibility study. 17(2), 223-233.

McLeod, S. (2007). Maslow's Hierarchy of Needs. Retrieved 2013. In.

Mentec, H., Dupont, H., Bocchetti, M., Cani, P., Ponche, F., \& Bleichner, G. J. C. c. m. (2001). Upper digestive intolerance during enteral nutrition in critically ill patients: frequency, risk factors, and complications. 29(10), 1955-1961.

Milanesi, R., \& Caregnato, R. C. A. J. E. (2016). Intra-abdominal pressure: an integrative review. 14(3), 423430 .

Mohamed, W. Y., abdel Mageed, E., Mehany, M. M., Mohammed, M. A., El-Hafez, A. I. A. J. J. o. E., \& practice. (2013). The Effect of two Schedules of Intermittent Enteral Feeding on the Development of Gastric Colonization. 4.

Momenfar, F., Abdi, A., Salari, N., Soroush, A., \& Hemmatpour, B. J. J. o. i. c. (2018). Studying the effect of abdominal massage on the gastric residual volume in patients hospitalized in intensive care units. $6(1), 47$.

Moreira, T. V., \& McQuiggan, M. J. N. i. C. P. (2009). Methods for the assessment of gastric emptying in critically ill, enterally fed adults. 24(2), 261-273.

Morton, P. G., \& Fontaine, D. K. (2013). Essentials of Critical Care Nursing A Holistic Approach: Wolters Kluwer Health| Lippincott Williams \& Wilkins.

Newcombe, J., Mathur, M., \& Ejike, J. C. J. C. c. n. (2012). Abdominal compartment syndrome in children. 32(6), 51-61.

Persenius, M. W., Larsson, B. W., Hall-Lord, M.-L. J. I., \& Nursing, C. C. (2006). Enteral nutrition in intensive care: nurses' perceptions and bedside observations. 22(2), 82-94.

Preece, J. J. C. T. i. N., \& Midwifery. (2002). Introducing abdominal massage in palliative care for the relief of constipation. 8(2), 101-105.

Pyszora, A., \& Krajnik, M. J. A. i. P. M. (2010). The role of physiotherapy in palliative care for the relief of constipation - a case report. 9(2), 45-47.

Ros, C., McNeill, L., \& Bennett, P. J. J. o. c. n. (2009). nurses can improve patient nutrition in intensive care. 18(17), 2406-2415.

Sinclair, M. J. J. o. b., \& therapies, m. (2011). The use of abdominal massage to treat chronic constipation. 15(4), 436-445.

Taylor, R. W. J. C. c. c. (2016). Gut motility issues in critical illness. 32(2), 191-201.

Uysal, N., Eser, I., \& Akpinar, H. J. G. N. (2012). The effect of abdominal massage on gastric residual volume: a randomized controlled trial. 35(2), 117-123.

Uysal, N. J. E. J. o. I. M. (2017). The effect of abdominal massage administered by caregivers on gastric complications occurring in patients intermittent enteral feeding-a randomized controlled trial. 10, 75-81.

Vazquez-Sandoval, A., Ghamande, S., Surani, S. J. W. j. o. g. p., \& therapeutics. (2017). Critically ill patients and gut motility: Are we addressing it? , 8(3), 174.

Wang, T. J., Wang, H. M., Yang, T. S., Jane, S. W., Huang, T. H., Wang, C. H., . . health. (2015). The effect of abdominal massage in reducing malignant ascites symptoms. 38(1), 51-59.

Warren, M. J. E.-b. n. (2016). Abdominal massage may decrease gastric residual volumes and abdominal circumference in critically ill patients. $19(3), 76-76$. 